\title{
Industrial Heritage Conservation in Urban Transformation for Sustainable Development
}

\author{
Qianyi Zhu* \\ No.8 Bolin, Xiakou, Nan'an District, Chongqing, 400072, China \\ katherineqyzhu@gmail.com
}

\begin{abstract}
Keywords: Industrial heritage, landscape urbanism, livable city, ecological transformation, sustainable development

Abstract. In 20 century, traditional industrial city intends propose ecological transformation while it realizes the environmental crisis. They face to the new challenge of global urbanization and have to continue the industrial activities. They prefer to hand on the characteristic context culture of the city while ecological transforming. This paper try to discuss conservation of industrial heritage contributing to mental culture and corporeal legacy, in order to improve its importance and the methodology. We attempt to give a proposal of characteristic post-industrial city based on ecological urbanism. For that, paper references to a mining land's transformation case of urban design for Lockport which is an urban study of 'Liquid Urbanism: New York Region+ Erie Canal'.
\end{abstract}

\section{Introduction}

In 1980s, accompanying traditional industrial production were shut down, considerable effort has led to modernization and diversification of the economic base at the Ruhr. In 1990s, Britisher earlier attempts to regenerate Deptford Creekside, by the way of the Single Regeneration Budget (SRB) programs resulted in a positive legacy (Deptford Creekside Charrette). Unlike the invention of steam engine revaluating the mode of production and bringing industrial time speedily, the process from industrial time to post-industrial time takes a long time. Many developed countries or regions society have begun to carry on this kind of transformation or they have accomplished the alteration.

It cannot be ignored that during Chinese urbanization, in many cities, especially megacity, they are carrying on similar actions of this kind of transformation, even we couldn't define instantly that it is or will be in the post-industrial time basing on data. From 2005 to 2010, Shoudu Iron and Steel Company were moved to Caofeidian. Until June 2011, Chongqing Iron \& Steel (Group) Co. Ltd. (CISC) finished removing from Dadukou to Changshou. Traditional industrial city is facing to a transformation under the new type of economic environment. Many these kinds of cities choose to move the industrial site out of the urban fabric, which including factories, mills and large quantity of accessorial zones. The cities overindulgent into the narrow modernism, that they imitate and compete with each other blindly, and ignore the unique characters as a negative factor to the city. As canceling a polluted point in the city, while the factories' disappearing, the old sites are reused as luxury residential site, shopping mall or new CBD because that the old industrial site always located on amazing land with stunning natural landscape and convenient infrastructure. Sometimes, the rare industrial heritage and culture is abandoned by the city.

This paper discusses conservation of industrial heritage contributing to mental culture and corporeal legacy, and attempts to study one question: how to create a characteristic post-industrial city based on ecological urbanism? It is referenced to two questions: how to do a new presentation of industrial culture in post-industry time in the traditional industrial city? How to hold the balance point between preserving industrial heritage site and approaching ecological transformation? 


\section{Transformation \& Particular 'post-industry'}

In 20th century, thriftily industrial production bequeathed many metropolises while scared the earth surface which was hard to recover. Then, accompanying the development and downfall of traditional industry, many problems emerged, such as environmental crisis and unemployment. Some celebrated heavy industrial region where were the economic and social cultural center of the world began to a series of transformation.

Ruhr in Germany is a representative and successful case where use to be one of the most famed industrial and economic region of the world, originally based on coal mining and steel production. Since 1970s, the heavy industry there got downfall what caused job losses in steelworks and coal mines. Many people have left the area, e.g. cities such as Dortmund, due to economic and associated social problems. And the area faced an awful environmental problem for the heavy industry including waste tips from coal mining, air and water pollution while the raw materials and resource were exhausted. After transformation and recovering, nowadays, the 'Ruhrpott' is once more a thriving region and an enormous urban area benefiting from its industrial mix of energy production, environmental technologies and modern service industries.

A subsequent case is Deptford Creek Site located in London. Deptford has been the site of bad neighbor activities since before the Doomsday book of 1085; it was known as "dirty Deptford" for the industrial period (Deptford Creekside Charrette). Greenwich Sewage Pumping Station here built in 1865, was an important element in Bazalgette's great scheme for removing London's sewage. City designers attach importance to Creekside location and historical value, and propose a Waterworks' Park to be recreational uses such as sports, and cultural uses and music events where would be the heart of Creekside.

In retrospect, the word 'post-industry' is earlier in Latin American social philosopher Ivan Illich's book 'Tools for Conviviality' [1] and DenielBell's popularization through his work 'The Coming of Post-Industrial Society' [2] in 1973. Due to the argument about the 'post-industrial society', the term has grown and changed. Most of the discussion concentrates on the economic structural relationship between manufacturing and intangibles produces. Until now, it is hard to define the word chronologically and is criticized as just a neologism. To concluding the characteristics theoretically, post-industrial society passes through a phase of society predominated by a manufacturing-based economy; economy undergoes a transition from the production of goods to the provision of services; behavioral economics and information technologies are developed.

It seems that many traditional industrial areas are on the way to post-industrial time or have accomplished the transformation. This kind of alteration reminds me the classical theory in 'Das Kapital' from Karl Marx, which is 'primitive accumulation of capital'. It tells us the process of primitive accumulation of capital is bitter, lengthy and obligatory. Industrial time just likes the period of primitive accumulation of capital. As it is inescapable, a megacity always used to be industrial city, in which period it accumulated wealth. How about that in China? We have two questions: Does the city have finished the process of 'primitive accumulation of capital'? The traditional industry of the city has passed away? Based on the data, to many traditional industrial cities, the producing activity is still the primary driving force for city's development which is at least displayed on the tax and economic structure. For instance, in Dadukou, Chongqing, the burgeoning municipalities in west China directly under the central government, more than half of the citizen work for Chongqing Iron \& Steel (Group) Co. Ltd. (CISC). And it occupies more than $80 \%$ local Industrial Production Value. Even until 2006, the last year before moving, that proportion still up to more than 50\% with the 640 million RMB what contributes $25.5 \%$ of the local tax. However, the globalization pulls this kind of city by developing new advanced techniques and the factory is ordered to applicate lower polluted and consumed production mode. When people realize the environmental crisis and own better capability to renovate the production mode, they began to change nevertheless the traditional industry is energetic and, still, the protagonist in local economy. At this time, the industrial heritage in this kind of city is not only historical legacy, but also existent and full-bodied industrial live modality and atmosphere. Therefore, while the city is marked to be in 'post-X time', such as 'post-CISC time', that ' $X$ ' stands for local major traditional industry, we mention it as particular 'post-industrial time' with a little bit different from the 'stander' post-industrial society. 
For huge action in China, Shoudu Iron and Steel Company in Beijing is a representative case, which is moved from Beijing city to Caofeidian due to support melioration of environment for 2008 Beijing Olympic Games. After losing the major traditional industry, accompanying transformation of economic structure, Beijing chooses to develop its 'soft-industry' presented by produced service and cultural originality. The original site will be proposed as 'West City Service Center' and 'Original Industrial District of Post-industrial Culture'. CISC, mentioned above, is a large-size steel complex boasting a history of more than one hundred years. The industry layout of "North China boasting Ansteel while South China boasting CISC" in New China spoke volumes for the essential status of CISC in national economic recovery. The produced activities of CISC are the primary origin of pollution what affect the quality of core city's environment. Therefore, the removing from Dadukou to Changshou of CISC is determined by the government of Chongqing in 2007. In three years, CISC has finished the phase 1 action, which is moving the old industrial site in Dadukou district where the industrial activity will be stopped in September 2011. As the local government presented on web, after shifting of CISC, two thematic parks will be proposed in the industrial heritage site that the one is

Riverside Park within boulevard beside the Chang River and the other one is Industrial Heritage Park involving a mini-counterpart of the steel produced equipment to show the whole process of traditional steel industry.

\section{Industrial City \& Livable City}

In 1933, some excellent architects and urban planners including Le Corbusier published 'Athens Charter' on the fourth congress of CIAM, which stated that the core goals of the Functional City is residence, work, tourism and transportation. The first request for urban planning is to solve the residence of the city. All the architects and urban designer are doing nothing but propose a livable city no matter what is the status of the city. If to discuss the issue in a particular background which is traditional industrial city, it could be partly contribute to two issues: livable urban fabric and industrial heritage.

Livable city factor. It is a little bit embarrassed to define the word 'livable' because that is up to you that citizen will give different realization to the definition. However, there are some recognized livable factors which we could conclude follow points also for sustainable development:

- Green system: A green system which can afford diversified activities of different ages is the key of green urbanism [3] and distinction from the wild. People who live in the traditional industrial city covered by concrete for a long time always yearn for natural environment. On the other hand, if the habitants move to mountain side where no business, no high-rise and no automobile has at all for a long time, I guess some of them will miss the neon lights and rock-and-roll. So the ecological space that we need in urban is not simplex and unilateral planting trees in soil, but organic space fabric which includes parks in city involving green and water, green corridor crossing the city and ecological belt connecting city and nature as infrastructure. $[4,5]$ -Open space: Open space may be both greenway or park that it emphasis function more. Jan Gehl claims 'Life Between Buildings' [6] that 'Open spaces stimulate the outdoor activities of the dwellers. Outdoor activities in public spaces can be divided into three categories, each of which places very different demands on the physical environment: necessary activities, optional activities and social activities.'(Figure 1) To service the different habitats activities, the public space includes squares and parks which is in city center or in the suburb area for entertainment, education or sport. The previous one affects citizen's daily life, and the other one defines the urban edge what limits urban sprawls a certain extent. 


\begin{tabular}{|c|c|c|}
\hline \multirow{2}{*}{} & \multicolumn{2}{|c|}{ Quality of the physical environment } \\
\cline { 2 - 3 } Necessary activities & Poor & \\
\hline Optional activities & $\bullet$ & \\
\hline $\begin{array}{c}\text { 'Resultant' activities } \\
\text { (Social activities) }\end{array}$ & & \\
\hline
\end{tabular}

Figure 1: Graphic representation of the relationship between the quality of outdoor spaces and the rate of occurrence of outdoor activities. When the quality of outdoor areas is good, optional activities occur with increasing frequency. Furthermore, as level of optional activity rise, the number of social activities usually increases substantiallv (Jan Gehl. 1980).

- Convenient transportation: Transportation is another major require of the functional city. In traditional industrial city, there must be convenient transportation for industrial activities. After transformation, city center may be transferred, land use is altered and the transportation net has to be modulated. Traditional industrial city always has developed transportation system, which could be its dominance on this issue.

- Sane infrastructural system: As Sten Allen's words, in architecture and urbanism, technique does not belong to an individual but to the discipline as a whole. A sane infrastructural system of the city will be increasing important while it is transforming to living mode from produced mode due to more complex population structure, and that infrastructural work recognizes the collective nature of the city and allows for the participation of multiple authors (Sten Allen, 1999) [7]. The infrastructure system is the insurance for healthy application of social urban as a complex machine for new multiplex cultures and diversiform economic market.

- Comfortable micro-weather: The longitude and latitude determines the local weather that we have to accept and adopt. But micro-weather could be benefited by enough proportion of ecological urban space and reasonable structure of different land use in the city. After the 'primitive accumulation of capital', in traditional industrial city, the natural environment is awful but feasible for reviving.

On the way of transforming to post-industrial social mode and ideology, people do nothing but pursuing a more wonderful and comfortable live environment involving above stunning aspects. The unique stander and goal marked the modern urbanism when brings strong empirical what supports the propinquity of development and regeneration. Then they overindulgent into the narrow modernism what is to imitate and compete with each other blindly, and ignore the unique characters as a negative factor to the city. This is not simple critique to modernism. Actually, as DanielZ. Sui asserts, 'scholars pursuing research under the banner of the Chicago School share a common theoretical framework (urban/ human ecology) and generally accepted methodological procedures to validate and replicate their claims. That is why the Chicago School has contributed enormously to our understanding of how cities work and has exerted far-reaching influences in numerous branches of the social sciences.' [8] Like the evolution of the Chicago School, modernism is either an unshakable religion for architecture and urbanism. The paradoxical competition just associates the cognition and implementation because of the inadequacy of speculation and self-appreciation. Therefore, shall we emphasis a plus point when the traditional industrial city rushes to the uniform modality hastily?

New type industrial site and its interplaying with urbanization: This kind of new type industrial site rooms derivative industry of tradition with new advanced technique and related industrial service infrastructure, institute and energy production. It could surmount the contradiction between industrial and ecological urbanism while reforming their relationship to be dialectic unify. Furthermore, the city may return to the trail of industry, and the livability achieve bidirectional promotion and benign cycle that industry supports ecological urbanism by economic motive power and livable city supplies produced activities' insurance by comprehensive social functions. 
Industrial heritage. 'Livable urban fabric' is really a complex, sophisticated and huge issue while 'industrial heritage' is a concrete, contextual and both negative and positive for the previous one. Industrial heritage claims binary contexts that one is the cultural heritage dealing specifically with its traditional industrial history, the other one is the buildings and artifacts of industry which affects people and their family while handing on generation by generation. Generally, we could contribute the it into two parts - the material heritage and mental heritage.

-New presentation of industrial culture. When I was a child, I lived in a traditional industrial city and most of my classmates' parents both worked in the factory for which the city was established. Consequently, they lived in the same site and they were, sometimes, along at home after school because parents' night duty (there always are worker on duty as the machine cannot be stop frequently, the work in factory is separated into three of runs, morning shift, middle shift and night shift). I still remember my perplexity when I listened the word 'molten steel' as a child from my classmate's composition. Nevertheless I understood in the next second that they know the word 'molten steel' just like that I was familiar with the work of a teacher for family's affection. That is one kind of saturation of industrial cultural in traditional industrial city. The typical congregated dwelling site, the mode of three of runs for work and the exerting subtle influence on the ideology of next generation, all that are evolved as industrial culture which is already in the life, bone, blood and behaviors of the citizen. That could be analogy with that Parisian prefer to enjoy life in coffee bar and the Austrian love dessert.

The cultural infiltration is a process of natural development. Accompanying the application of transformation, traditional industry is disappearing in the city where use to cohere to the produced activities, because of the losing of carrier. This is a predictable result of natural development for industrial heritage after interrupting by control development - urban transformation. However, this kind of control development also can renovate while conserving industrial culture. Both Ruhr and Deptford Creekside are successful cases due to the contextual speculation what stimulates continued speculation. Another amazing case is Te Puna Quarry Park which is situated at Te Puna, 12 kilometers north of Tauranga in the Bay of Plenty, north island of New Zealand, at the end of Quarry Road. This site of 32 hectares was reserved for 'quarry purposes' by Government Gazette notice in 1911 as Crown Land vested in the then Tauranga County Council. The rock in this quarry is a rhyolite material which is generally regarded as poor quality and did not satisfy specifications for good quality crushed base course road metal by the National Roads Board. Nowadays this quarry park is famous from its ecological plants rooming walking tracks, sculptures, picnic areas, gardens, specialty plant areas and places to explore.

To establish educated environment artificially including museum and conservation old machine partly is one good and feasible way to represent the industrial culture in ecological transformation. And to realize the industrial mining and culture contrasting to the achievement of ecological alteration is impressed. That could be another contribution of industrial heritage.

-Industrial heritage site. Industrial activities leave us some negative conditions, such as a lot of poor factories and large-scale nude-soil from mining. This kind of brownfield is facing to polarization in new urbanization basing on different strategies. The one is to be revived and the other one is to be a 'grey area' of the city which is full of crime and pollution.

Some industrial heritage site is located on stunning land with convenient transportation and picturesque vista where worth a lot if construct new business center or luxury residential site. Calling for protecting industrial heritage does not mean that we will alter the theme of regeneration from one polar point to the contrast one that building museum everywhere what will perform the urbanization as a show of creating counterpart. Therefore, to the modern business center or dwelling building which is established on the industrial heritage site, we shouldn't give a judgment unilaterally and simply that it is good or not, reasonable or not. Equally, we both shouldn't recognize the conservation to be remains what people will easily imagine the panorama if the site not to be relabeled. Absolutely, local government will harvest considerable income transitorily if the area is redeveloped to be real estate what is always done by the bureaucrats via selling the 
land to developers. This is undeniably economic energy but what I mentioned, that the points of livable city is public space which would be urban live energy and stronger economic drive power. For example, if to change riverside industrial heritage area to be public space, it seems that the dear land is occupied by landscape without creating economic value because of no investment from developers, or it limits the direct view to the water landscape of other buildings. But it enlarges the limited water landscape and lengthens the landscape edge which could raise the value of more vicinage. Hence, the essential issue here is appropriate public space that the character and industrial heritage could carry on, which is considerable economic income and sustainable way, because we need organic distributor of urban as public space.

\section{Industrial City and Livable City}

There is one point nailed down that ecological urbanism is the sustainable developed banner for urbanization. [9] Hence all those implementation or phenomenon calling for green space are accepted. Although, for implementation, considering realistic economic conditions, there is another problematic topic: how to hold the balance point between preserving industrial heritage site and approaching ecological transformation?

Nude soil and Vegetation The acreage of nude soil affects the environment directly via engendering dust. Many mining activities bring plentiful nude soil and this is really negative point for the city environment. Certainly, as habitats, we expect that the dust could be as few as possible and all the 'scars' on the earth from the mining would be covered by green or water. On the other hand, whole change in one night means abandoning all industrial history and reforming a huge environment artificially. Furthermore, transformation is complex and has to insure the steady transition of social economy, which means that we cannot stop the mining or other industrial activities sharply if it plays an important role in local economic structure. And it is really unwise that to carry on ecological transformation in whole large-scale brownfield blindly at the same time what will bring low livability of the plants. Upon those two aspects, the implementation should be in phases.

For instance, we did an urban study of 'Liquid Urbanism: New York Region+ Erie Canal' in 2010 relating searching opportunities and regenerating within restricted development zones and ecologically sensitive areas within the Erie Canalway Corridor. There are main two questions in the research: How does one address the issues of accessibility and transportation, urbanization and industrialization as one considers future typologies of water urbanism? How does one cultivate a framework - for presentation of historic and cultural resources - that addresses the environmental problems at the threshold between water systems and human settlements? Our group focused on Lockport where was established in 1825 and the first community was centered along the canal. The core of the city became a dramatic topographic relief which necessitated the engineering of a unique lock-system-known the Flight-of-Five. Today, Lockport is a city of 20,000 people, which is found in close proximity to large cities such as Buffalo and Rochester and needs to revive by promoting its most precious jewels, the Erie Canal and the Locks. We proposed a 600-acre quarry park locating at the edge of the city where mine was to transform the active industrial site into a park which will be extension of the city's ecological corridor.

The whole process will be implemented in three phases as Figure 2 showing. The first developed phase will focus on providing public access to the interior of the site and delineating the surface ecology of the site displaying a combination of natural and manmade elements and preparing ground for succession. The network of paths will follow the existing circulation transect allowing people to experience the site on bike, on foot. In the second phase, the park will provide a variety of spaces for social and physical activities. The programs include exhibition of public art and music performance space, playgrounds, fishing, bird watching areas, biking and nature trails. By the final phase, the park will support diverse habitats for birds, fish and native plant communities. Generally, in the process of the park's development, our aim is to correct natural habitat which was existing for maximizing ecological integrity and minimizing land degradation. [10, 11, 12] 


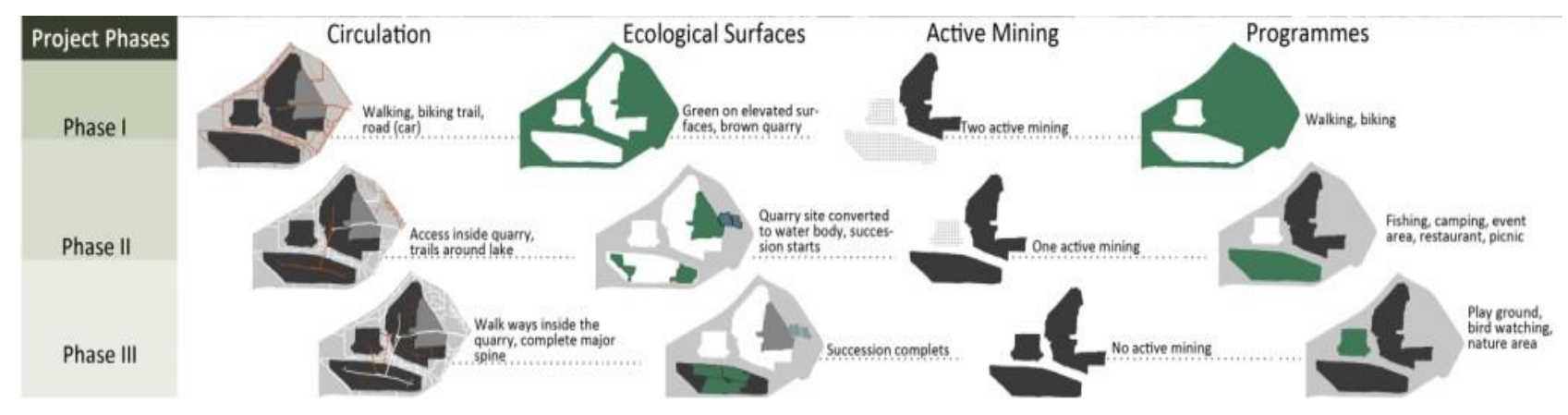

Figure 2: Proposal of ecological transformation on Lockport urban edge.

Conservation and Regeneration. To preserve industrial heritage site, it claims to continue the original figure while to revive a poor urban space prefers to alter its functions. History provided a ready-made catalog of 'meaningful' forms, but in order for the past to be appropriated and utilized, it had to be detached from its original context and converted into a sign (Sten Allen, 1999) [7]. I do not praise the cynical post-modernism theory [13] but we could adopt it on some extent for sustainable development because we could forecast the marginalization of the brownfield if it is not relabeled. Absolutely, we need a design within impetus to redevelop land corporeally, which could preserve industrial heritage by cognizable landscape or continued functional reuse. $[14,15]$

To preserve, as mentioned above, new type industrial site is a feasible way. For instance, after losing CISC, Dadukou develops Jianqiao new industrial district within picturesque environment and automobile industry, information technologies industry. Transformation of traditional industrial city does not mean to surrender industry totally due to its pollution. In contrast, we need to search an advanced industry to fill up the blankness in economic structure and social fabric. It is unwise that to remove industrial activities when we realize the environmental risk and ecological urbanism cannot be the reason of surrendering industrial district, especially when industry is still the major drive power of urban development. As the classical theory in China, it shouldn't step aside completely when opposite gain upon. Otherwise it will miss itself in the 'rattled footprints' at the end.

\section{Conclusions}

Industrial heritage is a mark figure of the traditional industrial city what could be displayed as industrial heritage site, abandoned factory, rusty rail, or particular infrastructure, and ideology infiltration into next generation. Regarding the context of city development is a healthy lived attitude, also a philosophy of survival and wisdom of development.

Heidegger has the follow sentence: 'What is the state of dwelling in our precarious age? On all sides we hear talk about the housing shortage, and with good reason... However hard and bitter, however hampering and threatening the lack of houses remains, the real plight of dwelling does not lie merely in the lack of house... The real plight lies in this, that mortals ever search anew for the nature of dwelling, that they must ever learn to dwell.' [16] As Heidegger marked 'learn to dwell'; now it is conceived as 'learn to live'. There are manifold changes happening every day and nothing will be completely perfect what cannot be the reason of blaming the external factors. Industrial heritage is really an idiographic issue in new urbanization of traditional industrial city, either an inescapable problem to industrial city in transformation. If there is something negative to urbanization in transformation, we could recognize it as an adversary who we need to learn to mediate it, appreciate it and affect it, at last, to use it for our purpose 


\section{Acknowledgements}

This work was financially supported by the 2014 Research Program of Chongqing Jianzhu College.

\section{References}

[1] Illich, Ivan (1973). Tools for Conviviality. ISBN 0-06-080308-8, ISBN 0-06-012138-6.

[2] Bell, Daniel, 1974, The Coming of Post-Industrial Society, New York: Harper Colophon Books

[3] Beatley, Timothy, 2000, Green Urbanism: Learning From European Cities, Washington (D. C.): Island Press

[4] Forman, Richard, 1990, 'Ecologically Sustainable Landscapes: The Role of Spatial Configuration', Changing Landscape: An Ecological Perspective, eds. Isaak S. Zonneveld and Richard T. T., New York: Springer-Verlag (reprinted in On Landscape Urbanism, Center 14, University of Texas at Austin School of Architecture 2007)

[5] WHEELER, STEPHEN M. \& Beatley, Timothy (eds.), 2009, Sustainable Urban Development Reader, Routledge Urban Reader Series, London: Routledge

[6] Gehl, Jan, 'Outdoor Space and outdoor Activities', Life Between Buildings, English translation. Copyright (C) 1987 by Jan Gehl. (reprinted by permission of Jan Gehl)

[7] Allen, Stan, 1999, 'Infrastructural Urbanism', Points+ Lines Diagrams and Projects for The City, New York: Princeton Architectural Press (reprinted in On Landscape Urbanism, Center 14, University of Texas at Austin School of Architecture 2007)

[8] Sui, Daniel Z., 1999, 'Postmodern Urbanism Disrobed: Or Why Postmodern Urbanism Is A Dead End for Urban Geography', Urban Geography, Vol. 20 No. 5, pp. 403-411

[9] RITCHIE, ADAM \& Thomas, Randall (eds.), 2009, Sustainable Urban Design: An Environmental Approach, London: Taylor and Francis

[10] Wall, Alex, 1999, 'Programming The Urban Surface', Recovering Landscape: Essays in Contemporary Landscape Architecture, ed. James Corner, New York: Princeton Architectural Press

[11] Wenche Dramstad, James Olson and Rechard Forman, 1996, (selected chapters) Landscape Ecology Principles in Landscape Architecture and Land-use Planning; Cambridge: Harvard University Graduate School of Design and Washington: Washington: Island Press and the American Society of Landscape Architects

[12] Corner, James, 1999, ‘The Agency of Mapping: Speculation, Critique, and Invention', Mappings, ed. Denis Cosgrove, London: Reaktion Books

[13] Heynen, Hilde, 1999, Architecture and Modernity. A Critique, London: MIT Press

[14] Corner, James, 1997, 'Ecology and Landscape as Agents ofCreativity', Ecological Design and Planning, eds. Geoge Thompson and Frederick Steiner, New York: John Wiley and Sons

[15] Waldheim, Charles, 2006, The Landscape Urbanism Reader, New York: Princeton Architectural Press

[16] Heidegger, Martin, 1971, Building Dwelling Thinking, New York: Harper Colophon Books 